\title{
The relation between glycated hemoglobin and severity of coronary artery disease in non-diabetic patients with acute coronary syndrome
}

\begin{abstract}
Aim: This study aimed to assess the relationship between HbA1c level and coronary artery disease (CAD) among non-diabetic patients.

Methods: One hundred patients with acute coronary syndrome (ACS) who referred to coronary angiography were included. According to American Diabetes Association (ADA7) patients were classified into high risk group (HbA1c $5.7-6.4 \%$ ) or low risk group $(\mathrm{HbA} 1 \mathrm{c}<5.7 \%)$. The severity of CAD was assessed by Gensini score which allocates a numerical value for the degree of coronary stenosis and a multiplication factor that depends on lesion location.
\end{abstract}

Results: The level of $\mathrm{HbA1} \mathrm{c}$ was positively correlated with Gnsini score $(\mathrm{r}=0.35, \mathrm{P}<0.05$, However HbAlc has no significant correlation with either RWMSI $(r=-0.09, \mathrm{p}>05)$ or $\operatorname{LVEF}(\mathrm{r}=-0.04, \mathrm{p}>0.05)$.

Conclusion: Among non-diabetic patients, higher $\mathrm{HbA} 1 \mathrm{c}$ is significantly correlated with the severity of CAD. HbA1c level has a prognostic value to predict the severity of CAD among non-diabetic patients.

Keywords: non-diabetic patients, coronary artery disease, glycated hemoglobin

\author{
Volume 8 Issue 4 - 2017
}

\author{
Reda Biomy, Waiel Twafeek, Ahmed \\ Abdelmoniem, Mohamed Abdelkader \\ Cardiology Department, Faculty of Medicine, Banha University, \\ Egypt
}

Correspondence: Reda Biomy, Department of Cardiology, Benha Faculty of Medicine, Benha University, Benha, Egypt, Tel 00 20III4383333,Email profreda59@yahoo.com

Received: October 24, 2016 | Published: March 17, 2017

\section{Introduction}

Diabetes mellitus (DM) is considered one of the most potent risk factors for cardiovascular diseases. The excess risk for cardiovascular disease is two to eight folds higher in patients with diabetes mellitus compared to non-diabetics of similar age, sex and ethnicity. ${ }^{1}$ High normal fasting blood glucose plus increased hemoglobin A1c $(\mathrm{HbA} 1 \mathrm{c})$ levels in non diabetics considered as potent risk factors for cardiovascular events. ${ }^{2}$ Glycated hemoglobin values reflect two to three months average endogenous exposure to glucose including postprandial spikes in blood glucose level and have low intraindividual variability particularly in non-diabetic patients. ${ }^{3} \mathrm{New}$ clinical practice recommendation from the American Diabetes Association (ADA) advocates the use of HbAlc in diagnosis of diabetes mellitus largely on the basis of the established association between Glycated hemoglobin and microvascular disease. ${ }^{4}$ Levels of $\mathrm{HbA} 1 \mathrm{c}$ less than $7 \%$ deemed appropriate for reducing risk of vascular complications. ${ }^{5}$ Predictive value of $\mathrm{HbA} 1 \mathrm{c}$ for coronary artery disease (CAD) severity and cardiovascular mortality in non diabetics had been widely studied since 2004. Many previous trials found that elevated $\mathrm{HbAlc}$ levels are correlated with CAD severity indicating it as a marker of extensive coronary arterial disease. ${ }^{6}$ In contrast, other studies found no relationship between $\mathrm{HbA1c}$ levels and the severity of CAD in nondiabetics with acute coronary syndrome. We aimed in the current study to investigate this relationship using Gensini scoring system. In 1983, Gensini et al., 7 suggested a scoring system, which depends on a numerical value for the degree of coronary artery stenosis, and this provides a detailed assessment of CAD and does not ignore even very trivial lesions in coronary arteries. ${ }^{7}$

\section{Patients \& methods}

This prospective study included 100 non diabetic patients who referred for doing coronary angiography within three months of acute coronary syndrome (unstable angina, Non ST segment elevation MI or
ST segment elevation MI). Diabetic patients or non diabetic patients with fasting blood sugar $>126 \mathrm{mg} / \mathrm{dl}$ or HbAlc more than $6.5 \%$ were excluded from the study. Included patients were subjected to complete medical history taking and physical examination with special emphasis on history of other risk factors as hypertension, smoking or family history of CAD. For all patients; 12 lead ECG, cardiac enzymes (troponin $\mathrm{T}$ and CK-MB), fasting blood sugar, HbA1c, lipid profile and serum creatinine. Transthoracic echocardiogram study was performed after admission to identify the estimated ejection fraction $(\mathrm{EF})$, regional wall motion abnormalities and associated valvular lesions. Regional wall motion score index (RWMSI) was calculated as the sum of wall motion scores divide by the number of the segments (normal $=1$, hypokinesis $=2$, akinesis $=3$, dyskinesis $=4$, and aneurysm=5). American Society of Echocardiography guidelines and recommendations were applied. ${ }^{8}$ Coronary angiography was performed using femoral or radial approaches. The severity of CAD was assessed by using the Gensini score. ${ }^{7}$ It is a scoring system which allocates a numerical value for the degree of stenosis in a coronary artery and a multiplication factor that depends on which coronary artery is involved and where the stenosis is located in the coronary artery (Table 1).

\section{Results}

Among total number of 120 screened patients as non diabetics, 12 patients were excluded as fasting blood sugar $>126 \mathrm{mg} / \mathrm{dl}$ or HbAlc more than $6.5 \%, 8$ patients were excluded because no evidence of CAD. Among 100 patients included, male gender pre dominated $(83 \%)$. Most of patients were overweight with mean $\mathrm{BMI}=29.7 \pm 4.9$. The most common cause of performing coronary angiography was unstable angina $(45 \%)$. The Gensini score ranged from (1 to 168$)$ with a mean of $38.3 \pm 34$.9. Seventy four patients were in high risk group with (HbA1c $5.7-6.4 \%$ ) while only 26 patients were in low risk group with $(\mathrm{HbA} 1 \mathrm{c}<5.7 \%)$. Other data of both 
groups were comparable (Table 1). Gensini score was found to be significantly higher in the high risk group (Figure 1). Using Pearson's correlation coefficients, the level of HbAlc was strongly correlated with Gensini score $(\mathrm{r}=0.35, \mathrm{P}<0.05)$ while $\mathrm{HbAlc}$ was weakly correlated with either RWMSI $(r=-0.09, \mathrm{p}>05)$ or LVEF $(\mathrm{r}=-0.04$, $\mathrm{p}>0.05$ ) (Table $2 \&$ Figure 2 ). The sensitivity of HbA1c in predicting severe coronary atherosclerosis (Gensini $>30$ ) was $68.2 \%$ while the specificity was $62.5 \%$ with a cut-off value of $6.05 \%$ (Figure 3 ).

Table I Demographic, clinical, laboratory \& echocardiographic data of both groups

\begin{tabular}{llll}
\hline Variables & $\begin{array}{l}\text { High risk } \\
(\mathbf{n = 7 4 ) 7 4 \%}\end{array}$ & $\begin{array}{l}\text { Low risk } \\
(\mathbf{n = 2 6 ) 2 6 \%}\end{array}$ & $\mathbf{p}$ \\
\hline Age & $54.6 \pm 7.7$ & $52.7 \pm 12.4$ & $>0.05$ \\
Male & $62(83.8 \%)$ & $21(8038 \%)$ & \\
Hypertension & $26(35.1 \%)$ & $1 \mathrm{I}(42.3 \%)$ & \\
Smoking & $56(75.7 \%)$ & $17(65.4 \%)$ & \\
Family history & $20(27 \%)$ & $4(15.4 \%)$ & \\
BMI & $29.9 \pm 4.9$ & $29.3 \pm 5.1$ & \\
Weight & $102.3 \pm 11.5$ & $102.04 \pm 13.2$ & \\
Unstable angina (\%) & $28(37.8 \%)$ & $17(65.4 \%)$ & $>0.05$ \\
NSTEMI (\%) & $19(25.7 \%)$ & $5(19.2 \%)$ & \\
STEMI (\%) & $27(36.5 \%)$ & $4(15.4 \%)$ & \\
FBG(mg/dl) & $95.3 \pm 16.8$ & $92.4 \pm 12.4$ & \\
TC(mg/dl) & $189.3 \pm 39.4$ & $187.7 \pm 4.5$ & \\
TGs(mg/dl) & $145.2 \pm 66.1$ & $151.3 \pm 64.4$ & \\
LDL(mg/dl) & $122.4 \pm 33.6$ & $119.9 \pm 44.2$ & \\
HDL(mg/dl) & $36.1 \pm 6.1$ & $36.3 \pm 4.7$ & \\
Creatinine(mg/dl) & $1.03 \pm 0.25$ & $1.05 \pm 0.28$ & \\
LVEF & $55.4 \pm 8.6$ & $56.9 \pm 10.4$ & \\
RWMSI & $1.15 \pm 0.2$ & $1.18 \pm 0.3$ & \\
Gensini score & $44.7 \pm 37.2$ & $20.3 \pm 17.8$ & \\
\hline
\end{tabular}

Table 2 Correlation between HbAIc and Gensini score, LVEF and RWMSI

\begin{tabular}{lllll}
\hline & & Gensini Score & LVEF & RWMSI \\
\hline HbAIc & $\begin{array}{l}\text { Correlation } \\
\text { coefficient }\end{array}$ & 0.35 & -0.04 & -0.09 \\
& Sig. (2-tailed) & $<0.05$ & $>0.05$ & $>0.05$ \\
& $\mathrm{~N}$ & 100 & 100 & 100 \\
\hline
\end{tabular}

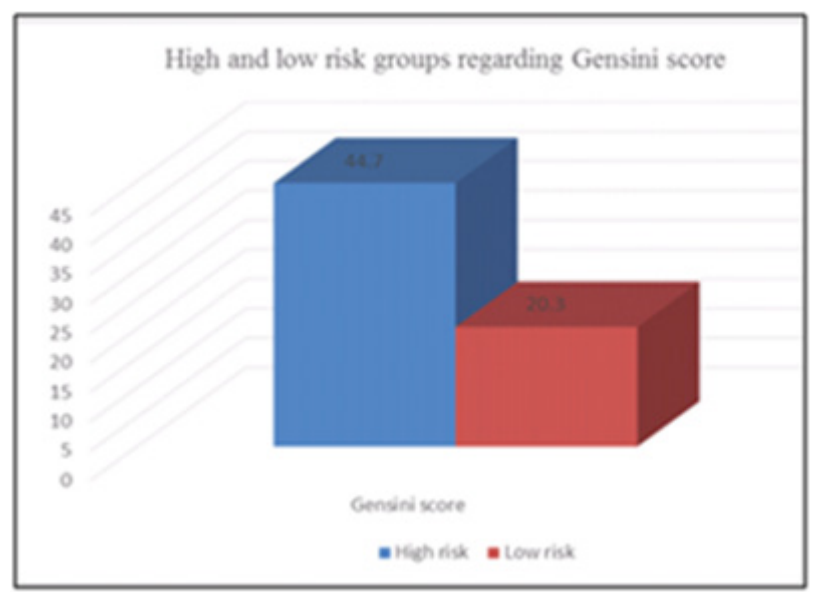

Figure I Comparison between high and low risk groups regarding Gensin score.

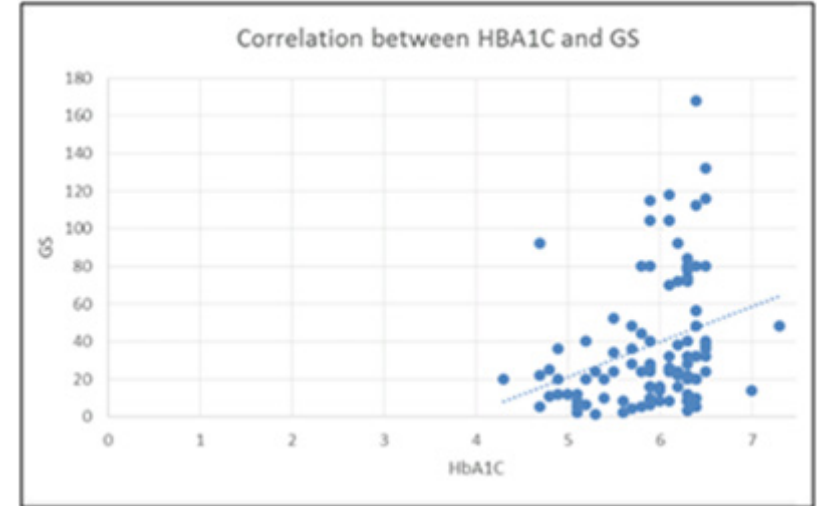

Figure 2 Correlation between $\mathrm{HbAlc}$ and Gensini score.

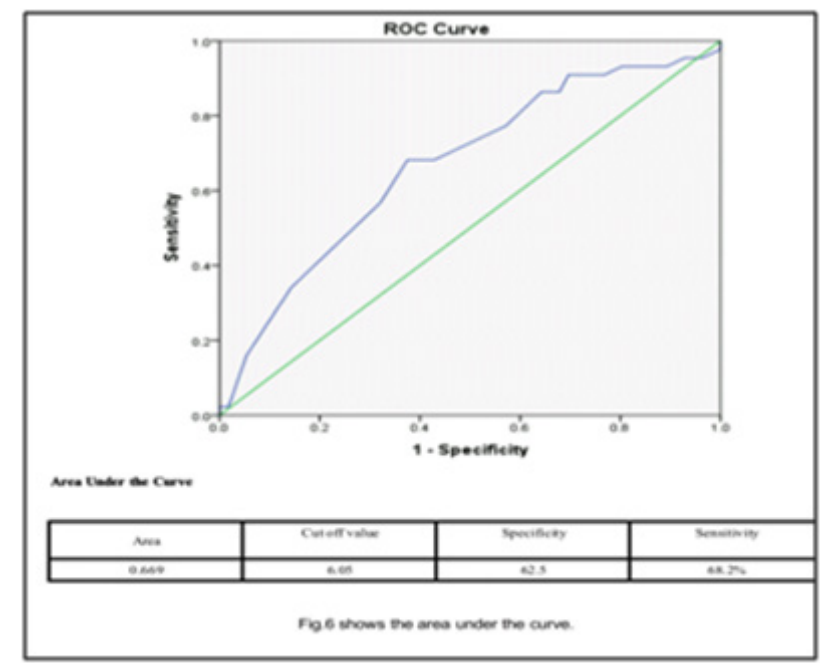

Figure 3 Receiver Operating Characteristic (ROC) Analysis.

\section{Discussion}

$\mathrm{HbAlc}$ is an established marker of long-term glycemic control in patients with DM. Elevated HbAlc levels associated with an increased risk for future microvascular \& macrovascular disease in diabetics. ${ }^{9}$ There is consistent evidence that optimal glycemic control (defined as $\mathrm{HbA} 1 \mathrm{c} \leq 7 \%$ ) results in a lower incidence of cardiovascular complications in both type 1 and type $2 \mathrm{DM} \cdot{ }^{10}$ In non diabetic patients, the predictive value of $\mathrm{HbAlc}$ for CAD severity was observed in previous trials since 2004. In the trial of Khaw et al., ${ }^{11}$ patients with $\mathrm{HbA} 1 \mathrm{c}$ concentrations less than $5 \%$ had the lowest rates of cardiovascular disease and mortality. An increase in HbAlc of $1 \%$ was associated with a relative risk for death from any cause of 1.24 (95\% CI, 1.14 to 1.34; P $<0.001) .{ }^{11}$ In 2010, Selvin et al., ${ }^{6}$ found that elevated HbA1c levels are predictive for cardiovascular events and mortality. Their results showed 20 to $30 \%$ increase in mortality and cardiovascular events with any increase in HbAlc level of $1 \%$ point. ${ }^{6}$ Rivera et al., ${ }^{12}$ studied the association between increasing levels of $\mathrm{HbAlc}$ and coronary plaque characteristics in asymptomatic individuals who diagnosed as non diabetics. Unadjusted analysis showed a positive association between increasing levels of HbAlc and the number of coronary segments $(\mathrm{p}<0.0001)$. The association persisted even when traditional risk factors were taken into account. ${ }^{12}$ Recently in 2014, Anping et al., ${ }^{13}$ conducted a study to investigate relationship between HbA1clevel and CAD severity in non-diabetic patients. Multivariate regression analyses showed that $\mathrm{HbA1c}$ 
strongly associated with the severity of CAD after adjustment for other traditional risk factors as well as fasting blood glucose. ${ }^{13}$

The current study aimed to assess the correlation between $\mathrm{HbAlc}$ level among non- diabetics who underwent coronary angiography and the severity of CAD. The novelty of current trial, that we used the Gensini score to assess CAD severity. We concomitantly evaluated the relationship between $\mathrm{HbA} 1 \mathrm{c}$ level and CAD severity including clinical scenario severity and the number of coronary artery stenosis. Consistent with previous studies, our results demonstrated that Gensini score was found to be significantly higher in the high risk group (Figure 2). HbAlc is positively correlated with the severity of CAD ( $\mathrm{r}=0.35, \mathrm{P}<0.05)$ (Table $3 \&$ Figure 3$)$. The sensitivity and specificity of $\mathrm{HbAlc}$ in predicting severe coronary atherosclerosis (Gensini >30) was high (Figure 4). There were different mechanisms might explain the correlation between level of $\mathrm{HbAlc}$ and $\mathrm{CAD}$ severity even in non diabetics. Increased $\mathrm{HbA} 1 \mathrm{c}$ level could reflect more generation of advanced glycosylation end-product, which might subsequently attached to vessel wall causing endothelial dysfunction and oxidative stress promotion. ${ }^{14}$ On the other hand, the binding of advanced glycosylation end-product might also result in inflammatory cytokines such as CRP over-production. ${ }^{15}$ Increased CRP level has been found significantly associated with the instability of plaque. ${ }^{16}$ Finally, increased advanced glycosylation end-product could interfere with endogenous fibrinolytic system which might result in higher risk of coronary artery stenosis. ${ }^{17}$ In contrast to the results of previous trials, Ahmet $\mathrm{G}$ et al., ${ }^{18}$ showed no significant relationship between $\mathrm{HbA1c}$ level and CAD severity ( $\mathrm{p}=0.299)$ in 65 non diabetic patients with acute myocardial infarction. They concluded that the extent of CAD did not differ significantly among subjects with normal glucose tolerance, impaired fasting glucose, or impaired glucose tolerance. ${ }^{18}$ To overcome this debate, Future clinical randomized studies are warranted to investigate whether reduced $\mathrm{HbA} 1 \mathrm{c}$ level will reduce the severity of CAD or not.

\section{Limitations}

Small number of the patients, No clinical follow up, the study does not show impact of fasting blood sugar or postprandial blood sugar on severity of CAD.

\section{Conclusion}

Current study demonstrated that higher $\mathrm{HbAlc}$ is significantly associated with the CAD severity among non-diabetic patients. $\mathrm{HbAlc}$ level is a useful marker and has a prognostic value to predict the severity of CAD among non-diabetic patients. It may be used as a cardiac marker in risk stratification of non-diabetic patients presenting with acute coronary syndrome and indicated for coronary angiography.

\section{Acknowledgments}

None.

\section{Conflicts of interest}

Author declares there is no conflicts of interest.

\section{Funding}

None.

\section{References}

1. Klein R. Hyperglycemia and microvascular and macrovascular disease in diabetes. Diabetes Care. 1995;18(2):258-268.

2. Nasir K, Santos RD, Tufail K, et al. High normal fasting blood glucose in non-diabetic range is associated with increased coronary arery calcium burden in asymptomatic men. Atherosclerosis. 2007;195:e155-e160.

3. Selvin E, Crainiceanu CM, Brancati FL, et al. Short-term variability in measures of glycemia and implications for the classification of diabetes. Arch Intern Med. 2007;167(14):1545-1551.

4. Elizabeth S. Glycated Hemoglobin, diabetes, and Cardiovascular risk in Nondiabetic Adults. N Engl J Med . 2010;362(9):800-811.

5. Selvin E, Coresh J, Shahar E, et al. Glycemia (haemoglobin A1c) and incident of ischemic stroke: the Atherosclerosis Risk in Communities (ARIC) study. Lancet Neurol. 2005;4(12):821-826.

6. Selvin E, Steffes MW, Zhu H, et al. Glycated hemoglobin, diabetes, and cardiovascular risk in nondiabetic adults. $N$ Engl $\mathrm{J}$ Med. 2010;362(9):800-811.

7. Gensini GG. A more meaningful scoring system for determining the severity of coronary heart disease. Am J Cardiol. 1983;51(3):606.

8. Podgoreanu, MV, Djaiani GN, et al. Quantitative echocardiographic assessment of regional wall motion and left ventricular asynchrony with color kinesis in cardiac surgery patients. Anesthesia and Analgesia. 2003;96(5):1294-1300.

9. Malmberg K, Rydén L, Wedel H, et al. Intense metabolic control by means of insulin in patients with diabetes mellitus and acute myocardial infarction (DIGAMI 2): effects on mortality and morbidity. Eur Heart J. 2005;26(7):650-661.

10. Stamler J, Vaccaro O, Neaton JD, et al. Diabetes, other risk factors, and 12 -yr cardiovascular mortality for men screened in the Multiple Risk Factor Intervention Trial. Diabetes Care. 1993;16(2):434-444.

11. Khaw KT, Wareham N, Bingham S, et al. Association of hemoglobin A1c with cardiovascular disease and mortality in adults: the European prospective investigation into cancer in Norfolk. Ann Intern Med. 2004;141(6):413.

12. Riveraa, Eue-Keun Choib, Yeonyee E Yoonb, et al. Association between increasing levels of hemoglobin A1c and coronary atherosclerosis in asymptomatic individuals without diabetes mellitus. Coronary Artery Disease. 2010;21(3):157-163.

13. Anping Cai, Guang Li, Jiyan Chen, et al. Glycated hemoglobin level is significantly associated with the severity of coronary artery disease in non-diabetic adults. Lipids Health Dis. 2014;13:181.

14. Brownlee M. The pathobiology of diabetic complications: a unifying mechanism. Diabetes. 2005;54(6):1615-1625.

15. Nathan DM, Cleary PA, Backlund JY, et al. Intensive diabetes treatment and cardiovascular disease in patients with type 1 diabetes. $N$ Engl J Med. 2005;353(25):2643-2653.

16. Geluk CA, Post WJ, Hillege HL, et al. C-reactive protein and angiographic characteristics of stable and unstable coronary artery disease: data from the prospective PREVEND cohort. Atherosclerosis. 2008;196(1):372-382.

17. Dunn EJ, Philippou H, Ariens RA, et al. Molecular mechanisms involved in the resistance of fibrin to clot lysis by plasmin in subjects with type 2 diabetes mellitus. Diabetologia. 2006; 49(5):1071-1080.

18. Ahmet Göktuğ Erte, Hüseyin Bağbanc1, Harun Kılıç, et al. Relationship between HbA1c levels and coronary artery severity in nondiabetic acute coronary syndrome patients. Arch Turk Soc Cardiol 2013;41(5):389-395. 